
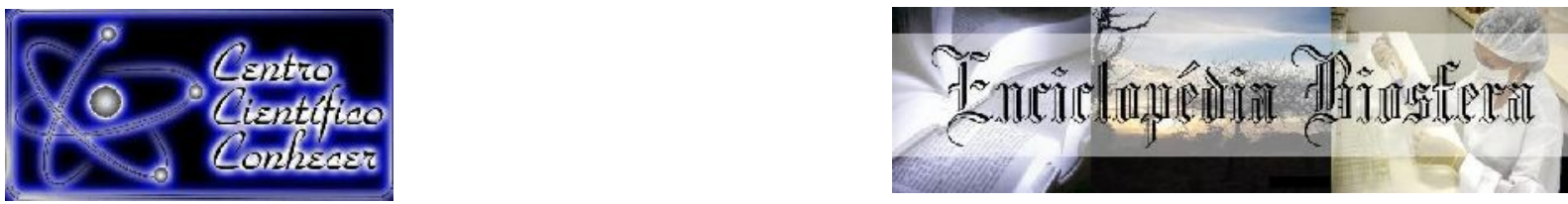

\title{
AUMENTO DE MASTÓCITOS PERITUMORAL EM NEOPLASIAS MALIGNAS METASTÁTICAS MAMÁRIAS CANINAS
}

\author{
Murilo Henrique Dias da Silva ${ }^{1}$, Gessica Tavares ${ }^{2}$, Bruno Dalbelo da Silva Elias ${ }^{2}$, \\ Geórgia Modé Magalhães ${ }^{3}$
}

- Graduando em Medicina Veterinária pelo Instituto Federal do Sul de Minas Gerais (IFSULDEMINAS), Campus Muzambinho, Muzambinho-MG.

- Graduandos em Licenciatura em Ciência Biológicas pelo Instituto Federal do Sul de

Minas Gerais (IFSULDEMINAS), Campus Muzambinho, Muzambinho-MG.

-Professora do Curso de Medicina Veterinária pelo Instituto Federal do Sul de Minas

Gerais (IFSULDEMINAS), Campus Muzambinho, Muzambinho-MG.

Email: murilohds850@outlook.com

Recebido em: 15/05/2021 - Aprovado em: 15/06/2021 - Publicado em: 30/06/2021

DOI: 10.18677/EnciBio_2021B7

\begin{abstract}
RESUMO
Os mastócitos podem ter papel importante no desenvolvimento de tumores mamários malignos, promovendo a angiogênese, semelhante ao que ocorre em alguns tumores da espécie humana. Nesse trabalho, pretende-se avaliar se a quantidade de mastócitos varia entre as neoplasias mamárias benignas, malignas, sítios metastáticos e a neoplasia primária desse sitio metastático. Mediante a aprovação do comitê de ética no uso de animais (CEUA) protocolo 44/2017, cortes de 3 a 4 micrômetros de amostras de neoplasias mamárias foram colocados em lâminas e corados com Hematoxilina e Eosina para classificação das neoplasias e com Azul de Toluidina para quantificação dos mastócitos. Após a quantificação realizou-se análise estatística com programa Graphpad Prism versão 8, utilizando teste t não pareado e considerando significativo um $p<0,05$. Não foi observada diferença estatística no número de mastócitos nas neoplasias benignas e malignas $(p=0,762)$. No tumor primário observou-se grande quantidade de mastócitos peritumoral enquanto esse valor diminuía significativamente na região intratumoral $(p=0,0008)$. Os mastócitos peritumorais não diferiram dos mastócitos localizados no sítio da metástase $(p=0,1621)$. Já os mastócitos intratumorais do tumor primário também estavam abaixo da quantidade de mastócitos no foco metastático $(p=0,0014)$. Conclui-se que a quantidade de mastócitos peritumoral nas neoplasias mamárias primárias metastáticas estão aumentados em relação aos mastócitos intratumorais dessas mesmas neoplasias. E os mastócitos no sítio metastático também estão aumentados em relação aos mastócitos intratumorais do local primário. Ao avaliar uma neoplasia primária metastática, a quantidade de mastócitos peritumorais pode indicar maior agressividade do tumor.
\end{abstract}

PALAVRAS-CHAVE: cão, inflamação, quantificação. 


\title{
INCREASE IN PERITUMORAL MAST CELLS IN CANINE BREAST METASTATIC MALIGNAL NEOPLASMS
}

\begin{abstract}
Mast cells may play an important role in the development of malignant breast tumors, promoting angiogenesis, similar to what occurs in some tumors of the human species. In this work, it is intended to assess whether the amount of mast cells varies between benign and malignant breast neoplasms, metastatic sites and the primary neoplasm of that metastatic site. Upon approval by the ethics committee on the use of animals (CEUA) protocol 44/2017, cuts of 3 to 4 micrometers of breast cancers were loved on slides and stained with Hematoxylin and Eosin to classify the neoplasms and with Toluidine Blue to quantify the mast cells. After quantification, statistical analysis was performed using the Graphpad Prism version 8 program, using unpaired t test and considering $p<0.05$ as significant. There was no statistical difference in the number of mast cells in benign and malignant neoplasms $(p=0.762)$. No primary tumor was observed, a large number of peritumoral mast cells while this value decreased occurred in the intratumoral region $(p=0.0008)$. Peritumoral mast cells did not differ from mast cells at the metastasis site $(p=0.1621)$. The intratumoral mast cells of the primary tumor were also below the number of mast cells in the metastatic focus $(p=$ 0.0014 ). It is concluded that the quantity of peritumoral mast cells in primary metastatic breast cancer is increased in relation to the intratumoral mast cells of these same neoplasms. And mast cells at the metastatic site are also increased compared to intratumoral mast cells at the primary site. When assessing a metastatic primary neoplasm, the amount of peritumoral mast cells may indicate greater aggressiveness of the tumor.
\end{abstract}

KEYWORDS: dog, inflammation, quantification.

\section{INTRODUÇÃO}

As neoplasias mamárias são o tipo neoplásico mais comum em cadelas (PASTOR et al., 2018), e o aumento da expectativa de vida dos cães está intimamente relacionado à maior incidência desses tumores mamários, principalmente os malignos (GONÇALVES et al., 2020).

Silva et al. (2019), verificaram que a maioria das neoplasias mamárias ocorrem em cadelas com mais de oito anos, representando $61,6 \%$ dos casos. Sendo observada, correlação da idade com o desenvolvimento de neoplasias malignas, grau histológico superior, ocorrência de necrose e metástase em linfonodo.

Oliveira et al. (2003), observaram uma incidência de neoplasias malignas de $71,8 \%$ dos casos, em fêmeas e Ariyarathna et al. (2018), Oliveira e Pandolfi (2020), verificaram que as neoplasias malignas mais frequêntes em cadelas são o tumor misto mamário, carcinoma simples e o carcinoma complexo, e as benignas são o adenoma simples e o adenoma cistico. Silva et al. (2019), não observaram predileção por raça, contudo os animais Sem Raça Definida, Poodles, Pinschers e Dachshunds foram os mais acometidos pelas neoplasias mamárias. 
Uma neoplasia é composta de células derivadas originalmente de tecidos normais, mas que devido a alterações genéticas herdadas deixaram de ser responsivas aos estímulos de crescimento normais, levando ao crescimento além dos seus limites anatômicos. Os tumores que não invadem tecidos vizinhos e não são capazes de migrar para outros tecidos são denominados benignos, geralmente são curáveis e raramente são responsáveis pela morte de seus hospedeiros. Os tumores que são capazes de invadir outros tecidos e se difundir por meio de metástases, são denominados malignos, quando não tratados, levam à morte do hospedeiro (KUSEWITT, 2013). Os cães de companhia por apresentarem neoplasias espontâneas podem ajudar na identificação de alvos antimetastáticos e descobertas de drogas clínicas (WEYDEN et al., 2019).

Muitas neoplasias mamárias podem ser evitadas com a ovário-histerectomia antes do primeiro estro, havendo apenas $0,5 \%$ desses animais desenvolverem. No entanto, o efeito protetor da ovário-histerectomia diminui após o primeiro estro e a maioria dos estudos não mostraram benefícios significativos quando realizada após os quatro anos de idade (SORENMO et al., 2020). A ovário-histerectomia após o aparecimento dos tumores não tem efeito protetor sobre o aparecimento de novos tumores, metástases ou sobre o prolongamento da vida do paciente. A prévia detecção desses tumores é de extrema importância na evolução do caso e para que se tenha um bom prognóstico (FONSECA; DALECK, 2000).

Cassali et al. (2020), no consenso sobre o diagnóstico, prognóstico e tratamento de tumores mamários caninos e felinos, postularam que o grau de estadiamento TNM e a avaliação dos fatores prognósticos clássicos, como: tamanho do tumor, contagem mitótica, grau e tipo histológico e envolvimento linfático apresentam grande valor na avaliação e prognóstico de cadelas com neoplasias mamárias. Alguns biomarcadores vêm sendo usados principalmente na detecção precoce das neoplasias mamárias e como valor prognóstico, porém na medicina veterinária ainda não é uma prática comum e mais pesquisas devem ser realizadas (KASZAK et al., 2018).

Apesar de muitos tumores passarem por um processo de inflamação, de modo geral, observa-se que a inflamação tem pouca ação protetora contra os tumores. Sendo que, muitas vezes, as próprias células tumorais ou células polimorfonucleares e mononucleares infiltradas, liberam quimiocinas e citocinas que atraem outras células inflamatórias ao tumor. Na neoplasia, essas células inflamatórias servirão de fonte de prostaglandinas, leucotrienos e espécies reativas de oxigênio (KUSEWITT, 2013).

Vale ressaltar, que atualmente os neoconceitos de microambiente tumoral e de inflamação associada aos tumores apontam para uma definição de câncer como uma complexa sociedade tecidual, onde a maioria dos integrantes trabalham para facilitar o crescimento da neoplasia, da suplantação da resistência imune e da disseminação metastática. Sendo assim, a neoplasia não exerce somente um controle interno sobre o ambiente tumoral, mas também externo ao tumor, influenciando o recrutamento de células circulantes para sustentar o crescimento e a disseminação da neoplasia. (FIGUEIREDO, 2019). Dessa forma a descoberta de novos biomarcadores tumorais permitirão maior conhecimento acerca do comportamento neoplásico e possibilitarão o desenvolvimento de terapias (RAPOSO et al., 2017). 
Lavalle et al. (2010), averiguaram que os mastócitos podem ter papel importante no desenvolvimento de tumores mamários malignos, promovendo a angiogênese, semelhante ao que ocorre em alguns tumores da espécie humana. Já Woldemeskel e Rajeev (2010), relatam que os mastócitos podem desempenhar importante função no desenvolvimento e progressão do hemangioma cutâneo canino, hemangiossarcoma, adenoma mamário e adenocarcinoma. Sendo necessária a realização de estudos detalhados que correlacionem a presença dessas células com a densidade de vasos.

Posto isso, pretende-se no presente trabalho, avaliar se a quantidade de mastócitos varia entre as neoplasias mamárias benignas, malignas, sítios metastáticos e a neoplasia primária desse sítio metastático, buscando elucidar o papel dessa célula na neoplasia, contribuindo assim com os estudos nessa área que apresenta grande importância para a saúde dos cães e dos humanos.

\section{MATERIAL E MÉTODOS}

Mediante a aprovação do comitê de ética em pesquisa (CEUA) protocolo 44/2017, foram selecionadas 10 amostras de neoplasias mamárias caninas benignas, 10 amostras de neoplasias mamárias malignas caninas sem metástase e sete amostras de metástase de neoplasias mamárias caninas e suas respectivas neoplasias mamárias primárias. As amostras pertenciam ao Laboratório de Patologia Animal do IFSULDEMINAS - Campus Muzambinho e estavam emblocadas em parafina.

Cortes de 3 a 4 micrômetros foram colocados nas lâminas e seguidos para a coloração de Hematoxilina e Eosina (HE) para classificação (CASSALI et al., 2019) das neoplasias benignas, malignas e metastáticas. Após a classificação em HE, as mesmas lâminas passaram pela coloração histoquímica de Azul de Toluidina para quantificação dos mastócitos.

Após coradas, os mastócitos foram contados em microscópio de luz binocular, utilizando-se a objetiva de 40x. Nas neoplasias benignas e malignas contou-se os mastócitos de 10 campos aleatórios ao redor e entremeando a neoplasia e fez-se a média dos mesmos por campo. Nas metástases, foram contados os mastócitos de 10 campos aleatórios ao redor do êmbolo tumoral da neoplasia mamária metastática e no tecido conjuntivo e tecido adiposo ao redor do linfonodo metastático e fez-se a média dos mesmos por campo. No tumor primário da metástase observou-se os mastócitos intratumorais e peritumorais e contou-se os mastócitos de 10 campos aleatórios.

A análise estatística foi realizada com o programa Graphpad Prism versão 8, com o teste $t$ não pareado. Os resultados foram considerados estatisticamente significativos quando $p<0,05$.

\section{RESULTADOS E DISCUSSÃO}

Não houve diferença estatística entre as comparações do número de mastócitos entre as neoplasias benignas e malignas $(p=0,762)$. Nas neoplasias mamárias benignas verificou-se uma média de 5,38 $\pm 4,26$ mastócitos por campo e nas neoplasias malignas

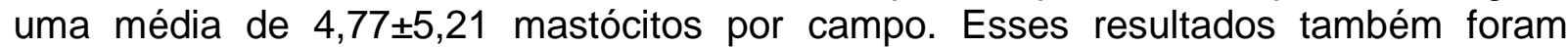
observados por Lavalle et al. (2010). 
Em relação aos tumores metastáticos foram feitas duas contagens de mastócitos no tumor primário metastático e uma contagem no local da metástase. No tumor primário observou-se grande quantidade de mastócitos localizados peritumoral com média de 11,62 $\pm 4,6$ (Figura 1A) enquanto esse valor diminuía significativamente quando os mastócitos estavam localizados intratumorais com média de 3,62 $\pm 3,02$, com valor de $\mathrm{p}=0,0008$ (Figura $2 \mathrm{~A}$ ). Em relação aos mastócitos peritumorais, esses não diferiram dos mastócitos localizados no sítio da metástase (Figura 1B) como ao redor de linfonodos e ao redor de êmbolos tumorais que apresentaram média de 16,86 $\pm 8,82$, com valor de $\mathrm{p}=0,1621$.

Já os mastócitos intratumorais do tumor primário também estavam muito abaixo da quantidade de mastócitos localizados no foco metastático com p=0,0014 (Figura 2B). Corroborando com o observado por Jana et al. (2017), em carcinomas mamários humanos, verificaram menor quantidade de mastócitos na neoplasia primária do que nas metástases, sendo observada uma média de 5,76 mastócitos por campo no nódulo mamário primário e 11,20 mastócitos por campo no linfonodo.

FIGURA 1. Fotomicrografia de mastócitos (setas) em neoplasias mamárias caninas coloração azul de toluidina aumento de 400x. A - observa-se região peritumoral de tumor primário metastático; B - linfonodo metastático.

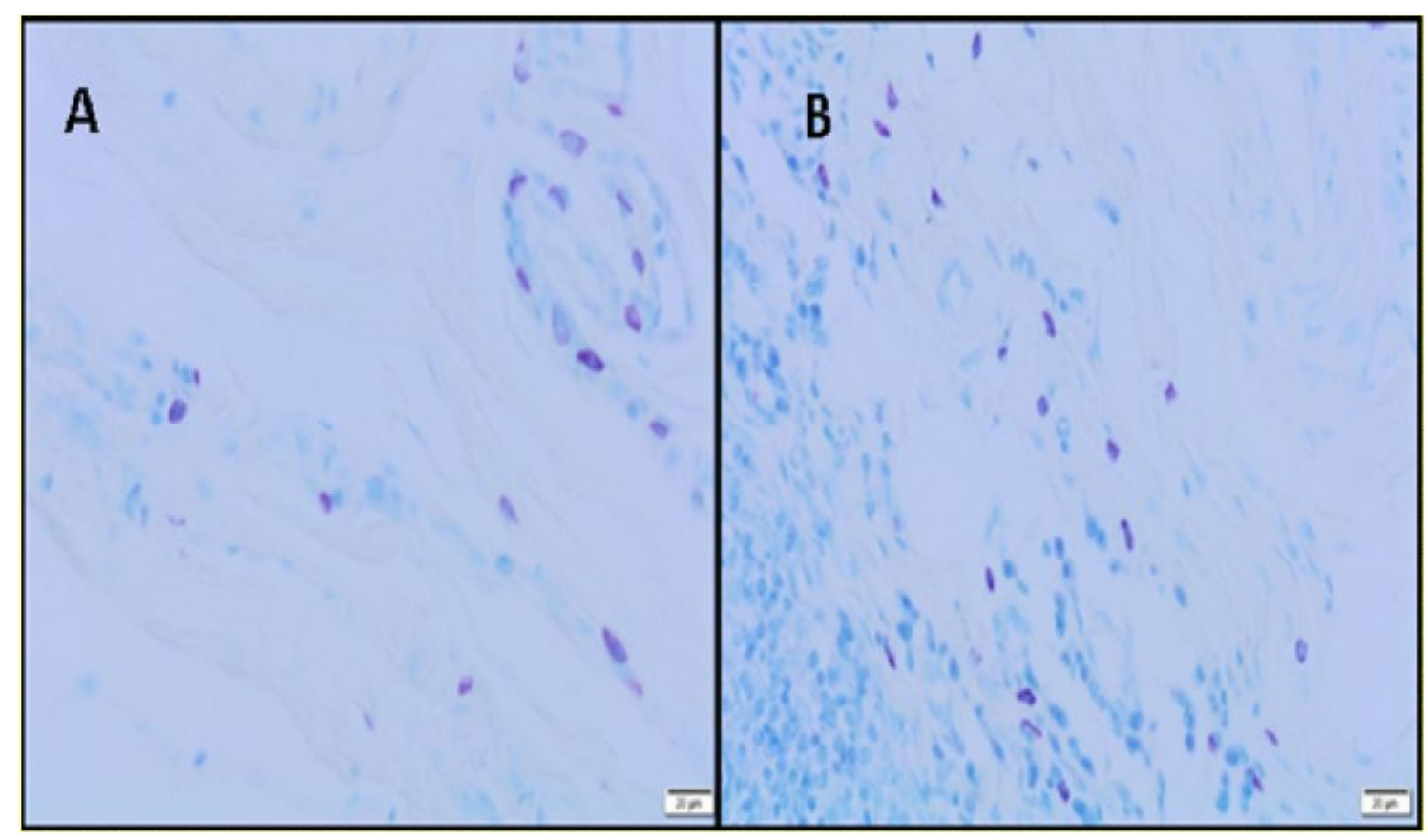

Fonte: Autores (2021) 
FIGURA 2 A e B. Quantificação de mastócitos por Azul de Toluidina em neoplasias mamárias caninas. Letras iguais não diferem pelo teste t, Graphpad Prism versão 8.

Tumor Metastático

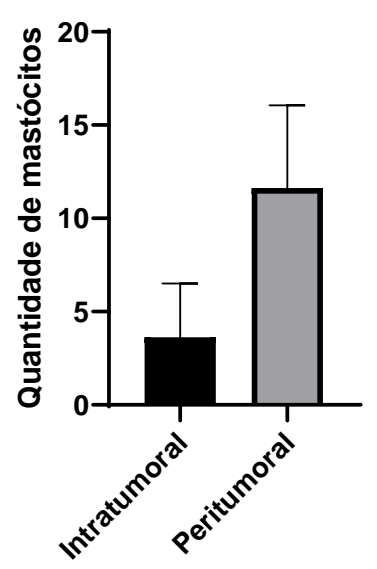

Localização do mastócito

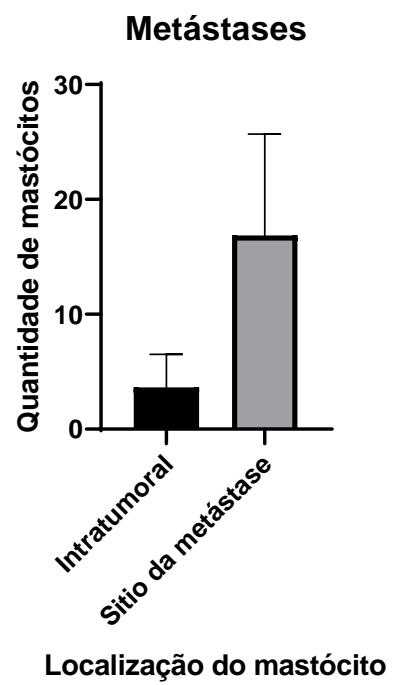

Fonte: Autores (2021)

As amostras de neoplasias mamárias benignas foram classificadas histologicamente em hiperplasia de células colunares, adenoma mamário cístico e tumor mamário misto benigno. As malignas em carcinoma papilar não invasor grau I, carcinoma tubular grau I e sólido grau II. A classificação das metástases é apresentada no quadro 1.

QUADRO 1. Tipo histológico e local da metástase das neoplasias mamárias caninas.

\begin{tabular}{|c|c|}
\hline Tipo histológico & Local da metástase \\
\hline Carcinoma papilar invasor grau II & Linfonodo \\
\hline Carcinoma papilar invasor grau II & Linfonodo \\
\hline Carcinoma anaplásico & Linfonodo \\
\hline Carcinoma anaplásico & Émbolo tumoral no tumor primário \\
\hline Carcinoma papilar invasor grau II & Émbolo tumoral no tumor primário \\
\hline Carcinoma em tumor misto grau III & Émbolo tumoral no tumor primário \\
\hline Carcinoma sólido grau II & Émbolo tumoral no tumor primário \\
\hline
\end{tabular}

O carcinoma anaplásico (Figura $3 \mathrm{~A}$ e B) é considerado um dos tumores mais agressivos em cadelas com tempo médio de sobrevida estimado de 3 meses (RASOTTO et al., 2017), concordando com os nossos resultados em que só foram encontrados nos casos metastáticos. Ainda em relação aos subtipos histopatológicos, autores encontraram o carcinoma em tumor misto como o tipo histológico mais frequente e de melhor prognóstico (NUNES et al., 2018). Em nosso estudo o carcinoma 
em tumor misto foi encontrado nos casos metastáticos e não metastáticos, variando o grau de malignidade.

FIGURA 3. Fotomicrografia de Carcinoma anaplásico mamário canino, coloração Hematoxilina e Eosina, aumento de 400x. A - tumor primário metastático; B êmbolo neoplásico.

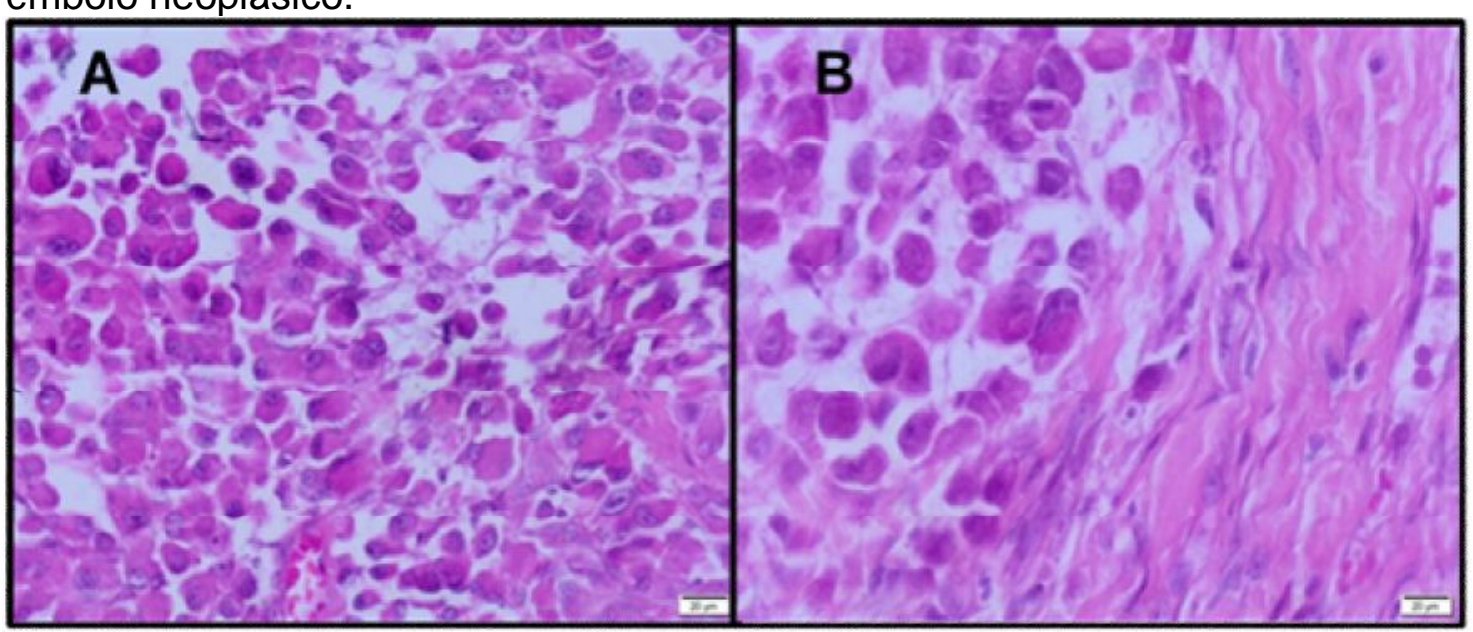

Fonte: Autores (2021)

Ariyarathna et al. (2020), verificaram que $81 \%$ dos tumores mamários malignos caninos com menos de 10 mastócitos por 10 campos de grande aumento metastatizaram posteriormente, enquanto apenas 9,5\% dos tumores malignos com mais de 10 mastócitos em 10 campos de grande aumento desenvolveram metástase. Neste estudo os tumores malignos que não levaram a metástase continham menos de 10 mastócitos em 10 campos de grande aumento.

Jana et al. (2017), verificaram que em humanos o número de mastócitos por campo foi menor conforme o grau do tumor aumentava, havendo uma inversa correlação entre o número de mastócitos e o grau do tumor. Já Rajput et al. (2007), concluíram que a presença de ao menos um mastócito no estroma tumoral se correlaciona com um bom prognóstico nos casos de mulheres com câncer de mama invasivo. Neste estudo verificou-se que o baixo número de mastócitos no estroma intratumoral se relacionou com a maior agressividade metastática.

Além disso, Sfacteria et al. (2011), em estudo com glândulas mamárias caninas normais, pré-neoplásicas e neoplásicas, observaram que os mastócitos estavam localizados no tecido conjuntivo. Sendo que na glândula mamária normal, os mastócitos eram dificilmente detectáveis e localizados principalmente no estroma intralobular. Nas lesões pré-neoplásicas foram mais numerosas tanto no estroma intralobular quanto no perilobular em comparação com o tecido normal. Nos carcinomas mamários, variou com base na localização: nas áreas intratumorais foram mais escassos enquanto aumentavam em número nas áreas peritumorais para ganhar maior número na borda de invasão da neoplasia. Neste estudo a maioria dos mastócitos se localizavam peritumoral nas neoplasias malignas metastáticas e nos locais da metástase. 
Em relação aos êmbolos neoplásicos os mastócitos estavam em volta. Não foram observados mastócitos nos linfonodos metastáticos e sim ao redor dos vasos linfáticos aferentes localizados no tecido adiposo. Vale lembrar, que os mastócitos secretam uma molécula chamada triptase, responsável por induzir a angiogênese (RIBATTI et al., 2003). Esta molécula também pode ser um agente mitogênico (ÖZDEMIR, 2006). Xiang et al. (2010) avaliando neoplasias mamárias em mulher, apontaram que houve um aumento da triptase associado ao maior grau do tumor e maior metástases nos linfonodos. A triptase promoveu a invasão e migração das células do câncer de mama junto com a ativação da metaloproteinase tipo 2, porém não afetou a proliferação celular, concluindo que a triptase promove a migração e a invasão do câncer de mama. Este estudo corrobora para o número aumentado de mastócitos analisado nas amostras de metástases.

\section{CONCLUSÃO}

Concluiu-se que a quantidade de mastócito peritumoral nas neoplasias mamárias primárias metastáticas está aumentada em relação aos mastócitos intratumorais dessas mesmas neoplasias. E os mastócitos no sítio metastático também estão aumentados em relação aos mastócitos intratumorais do local primário. Provavelmente esse aumento dos mastócitos em regiões peritumorais podem estar envolvidos com o processo de metástase contribuindo com a agressividade tumoral.

\section{REFERÊNCIAS}

ARIYARATHNA, H.; SILVA, N. de; ABERDEIN, D.; KODIKARA, D.; JAYASINGHE, M.; ADIKARI, R.; MUNDAY, J. Clinicopathological Diversity of Canine Mammary Gland Tumors in Sri Lanka: a one-year survey on cases presented to two veterinary practices. Veterinary Sciences, [S.L.], v. 5, n. 2, p. 1-12, 27 abr/2018. Disponível em: <http://dx.doi.org/10.3390/vetsci5020046>. doi: 10.3390/vetsci5020046.

ARIYARATHNA, H.; THOMSON, N.; ABERDEIN, D.; MUNDAY, J. S. Low Stromal Mast Cell Density in Canine Mammary Gland Tumours Predicts a Poor Prognosis. Journal Of Comparative Pathology, [S.L.], v. 175, p. 29-38, fev/2020. Disponível em: <http://dx.doi.org/10.1016/j.jcpa.2019.12.004>. doi: 10.1016/j.jcpa.2019.12.004.

CASSALI, G. D.; JARK, P. C.; GAMBA, C.; DAMASCENO, K. A.; ESTRELA-LIMA, A.; DE NARDI, A. B.; et al.,; Consensus Regarding the Diagnosis, Prognosis and Treatment of Canine and Feline Mammary Tumors - 2019. Brazilian Journal Of Veterinary Pathology, [S.L.], v. 13, n. 3, p. 555-574, set. 2020. Disponível em: <http://dx.doi.org/10.24070/bjvp.1983-0246.v13i3p555-574>. doi: 10.24070/bjvp.19830246.v13i3p555-574.

FIGUEIREDO, C. R. L. V. The unusual paradox of cancer-associated inflammation: an update. Jornal Brasileiro de Patologia e Medicina Laboratorial, [S.L.], v. 55, n. 3, p. 321-332, 2019. Disponível em: <http://dx.doi.org/10.5935/1676-2444.20190029>. doi: 10.5935/1676-2444.20190029. 
FONSECA, C. S.; DALECK, C. R. Neoplasias Mamárias em Cadelas: Influência Hormonal e Efeitos da Ovário-Histerectomia como terapia adjuvante. Ciência Rural, Santa Maria, v. 30, n. 4, p.731-735, 20 jul/2000. Disponível em: <https://doi.org/10.1590/S0103-84782000000400030.>. doi: 10.1590/S010384782000000400030.

GONÇALVES, R. O.; SANTOS, A. L. de S. L. dos; CHAGAS, J. D. R.; CRESPILHO, A. M.; ROIER, E. C. R.; LEITE, S. M. G.; MORAES, R. F. F. de. Neoplasias mamárias em cadelas: um estudo estatístico para auxiliar no tratamento. Pubvet, [S.L.], v. 14, n. 5, p. 1-7, mai/2020. Disponível em: <http://dx.doi.org/10.31533/pubvet.v14n5a566.1-7>. doi: 10.31533/pubvet.v14n5a566.1-7.

JANA, S.; GHOSH, S.; DE, A.; PAL, S.; SENGUPTA, S.; GHOSH, T.. Quantitative analysis and comparison of mast cells in breast carcinomas and axillary lymph nodes. Clinical Cancer Investigation Journal, [S.L.], v. 6, n. 5, p. 214-218, 2017. Disponível em: <http://dx.doi.org/10.4103/ccij.ccij_52_17>.doi:10.4103/ccij.ccij_52_17.

KASZAK, I.; RUSZCZAK, A.; KANAFA, S.; KACPRZAK, K.; KRÓL, M.; JURKA, P.. Current biomarkers of canine mammary tumors. Acta Veterinaria Scandinavica, [S.L.], v. 60 , n. 1, p. 1-13, 29 out/2018. Disponível em: <http://dx.doi.org/10.1186/s13028-0180417-1>. doi: 10.1186/s13028-018-0417-1.

KUSEWITT, D. F. Neoplasia e Biologia Tumoral. In: ZACHARY, J. F.; MCGAVIN, M. D. Bases da Patologia em Veterinária. 5. ed. Rio de Janeiro: Elsevier Editora Ltda., Cap. 6, p. 289, 2013. Tradução de EZ2 Translate e Serviços Ltda.

LAVALLE, G. E.; BERTAGNOLLI, A. C.; TAVARES, W. L. F.; FERREIRA, M. A. N. D.; CASSALI, G. D. Mast cells and angiogenesis in canine mammary tumor. Arquivo Brasileiro de Medicina Veterinária e Zootecnia, [S.L.], v. 62, n. 6, p. 1348-1351, dez/ 2010. Disponível em: <https://doi.org/10.1590/S0102-09352010000600008>. doi: 10.1590/S0102-09352010000600008.

NUNES, F. C.; CAMPOS, C. B.; TEIXEIRA, S. V.; BERTAGNOLLI, A. C.; LAVALLE, G. e; CASSALI, G. D. Epidemiological, clinical and pathological evaluation of overall survival in canines with mammary neoplasms. Arquivo Brasileiro de Medicina Veterinária e Zootecnia, [S.L.], v. 70, n. 6, p. 1714-1722, dez/2018. Disponível em: <http://dx.doi.org/10.1590/1678-4162-10217>. doi: 10.1590/1678-4162-10217.

OLIVEIRA, G. S.; PANDOLFI, I. A. Estudo retrospectivo dos exames histopatológicos realizados em cadelas com tumores mamários em hospital veterinário. Pubvet, [S.L.], v. 14, n. $8, \quad$ p. $1-8, \quad$ ago/2020. Disponível em: <http://dx.doi.org/10.31533/pubvet.v14n8a634.1-8>. doi: 10.31533/pubvet.v14n8a634.18. 
OLIVEIRA, L. O. de; OLIVEIRA, R. T. de; LORETTI, A. P.; RODRIGUES, R.; DRIEMEIER, D. Aspectos epidemiológicos da neoplasia mamária canina. Acta Scientiae Veterinariae, [S.L.], v. 31, n. 2, p. 105, 27 jun/2003. Disponível em: <http://dx.doi.org/10.22456/1679-9216.17079>. doi: 10.22456/1679-9216.17079.

ÖZDEMIR, Ö. Might mast cells have a role in neoplastic angiogenesis of canine melanomas?. Veterinary dermatology, v. 17, n. 4, p. 284-286, 2006. Disponível em: <http://dx.doi.org/10.1111/j.1365-3164.2006.00524.x>. doi: 10.1111/j.13653164.2006.00524.x.

PASTOR, N.; CABALLÉ, N. C.; SANTELLA, M.; EZQUERRA, L. J.; TARAZONA, R.; DURAN, E. Epidemiological study of canine mammary tumors: age, breed, size and malignancy. Austral Journal Of Veterinary Sciences, [S.L.], v. 50, n. 3, p. 143-147, 2018. Disponível em: <http://dx.doi.org/10.4067/s0719-81322018000300143>. doi: $10.4067 / \mathrm{s} 0719-81322018000300143$.

RAJPUT, A. B.; TURBIN, D. A.; CHEANG, M. C.; VODUC, D. K.; LEUNG, S.; GELMON, K. A.; GILKS, C. B.; HUNTSMAN, D. G.. Stromal mast cells in invasive breast cancer are a marker of favourable prognosis: a study of 4,444 cases. Breast Cancer Research And Treatment, [S.L.], v. 107, n. 2, p. 249-257, 13 mar/2007. Disponível em: <http://dx.doi.org/10.1007/s10549-007-9546-3>. doi: 10.1007/s10549007-9546-3.

RAPOSO, T. P.; PIRES, I.; PRADA, J.; QUEIROGA, F. L.; ARGYLE, D. J. Exploring new biomarkers in the tumour microenvironment of canine inflammatory mammary tumours. Veterinary And Comparative Oncology, [S.L.], v. 15, n. 2, p. 655-666, 17 jan/2017. Disponível em: <http://dx.doi.org/10.1111/vco.12209>. doi: 10.1111/vco.12209.

RASOTTO, R.; BERLATO, D.; GOLDSCHMIDT, M. H.; ZAPPULLI, V. Prognostic Significance of Canine Mammary Tumor Histologic Subtypes: an observational cohort study of 229 cases. Veterinary Pathology, [S.L.], v. 54, n. 4, p. 571-578, 29 mar/2017. Disponível em: <http://dx.doi.org/10.1177/0300985817698208>. doi: 10.1177/0300985817698208.

RIBATTI, D.; VACCA, A.; RIA, R.; MARZULLO, A.; NICO, B.; FILOTICO, R.; RONCALI, L.; DAMMACCO, F. Neovascularisation, expression of fibroblast growth factor-2, and mast cells with tryptase activity increase simultaneously with pathological progression in human malignant melanoma. European Journal Of Cancer, [S.L.], v. 39, n. 5, p. 666674, mai/2003. Disponível em: <http://dx.doi.org/10.1016/s0959-8049(02)00150-8>. doi: 10.1016/s0959-8049(02)00150-8.

SFACTERIA, A.; LANTERI, G.; GRASSO, G.; MACRÌ, B.; MAZZULLO, G. Mast cells in canine mammary gland tumour: number, distribution and epor positivity. Veterinary And Comparative Oncology, [S.L.], v. 9, n. 4, p. 310-315, 22 jun/2011. Disponível em: 
<http://dx.doi.org/10.1111/j.1476-5829.2011.00277.x>.

doi:

$10.1111 / \mathrm{j} .1476-$

5829.2011.00277.x.

SILVA, H. do C.; OLIVEIRA, A. R. de; HORTA, R. dos S.; MERÍSIO, A. C. R.; SENA, B. V. de; SOUZA, M. C. C. de; FLECHER, M. C. Epidemiology of Canine Mammary Gland Tumours in Espírito Santo, Brazil. Acta Scientiae Veterinariae, [S.L.], v. 47, n. 1640, p. 1-9, fev/2019. Disponível em: <http://dx.doi.org/10.22456/1679-9216.89901>. doi: 10.22456/1679-9216.89901.

SORENMO, K. U.; WORLEY, D. R.; ZAPPUL, V. Tumors of the Mammary Gland. In: VAIL, D. M.; THAMM, D. H.; LIPTAK, J. M. Withrow \& MacEwen's Small Animal Clinical Oncology. 6. ed. St. Louis: Elsevier, p. 604-625, 2020.

WEYDEN, L. V. D.; STARKEY, M.; ABU-HELIL, B.; MUTSAERS, A. J.; WOOD, G. A.. Companion canines: an under-utilised model to aid in translating anti-metastatics to the clinic. Clinical \& Experimental Metastasis, [S.L.], v. 37, n. 1, p. 7-12, 5 nov/2019. Disponível em: <http://dx.doi.org/10.1007/s10585-019-10002-5>. doi: 10.1007/s10585019-10002-5.

WOLDEMESKEL, M.; RAJEEV, S. Mast cells in canine cutaneous hemangioma, hemangiosarcoma and mammary tumors. Veterinary Research Communications, [S.L.], v. 34, n. 2, p. 153-160, fev/2010. Disponível em: <http://dx.doi.org/10.1007/s11259-010-9341-1>. doi: 10.1007/s11259-010-9341-1.

XIANG, M.; GU, Y.; ZHAO, F.; LU, H.; CHEN, S.; YIN, L. Mast cell tryptase promotes breast cancer migration and invasion. Oncology Reports, [S.L.], v. 23, n. 3, p. 615-619, 26 jan/2010. Disponível em: <http://dx.doi.org/10.3892/or_00000676>. doi: 10.3892/or_00000676. 